\title{
Exploration on digital marketing as business strategy model among Malaysian entrepreneurs via neurocomputing
}

\author{
Hazrita Ab Rahim', Shafaf Ibrahim², Saadi Bin Ahmad Kamaruddin ${ }^{3}$, Nor Azura Md. Ghani ${ }^{4}$, Ismail \\ Musirin $^{5}$ \\ ${ }^{1,3}$ Faculty of Business, Economics and Accounting, HELP University, Subang 2 Campus. Subang Bestari, Shah Alam, \\ Selangor, Malaysia \\ ${ }^{2}$ Faculty of Computer and Mathematical Sciences, Universiti Teknologi MARA, Jasin, Melaka, Malaysia \\ ${ }^{4}$ Faculty of Computer and Mathematical Sciences, Universiti Teknologi MARA, Shah Alam, Selangor, Malaysia \\ ${ }^{5}$ Faculty of Electrical Engineering, Universiti Teknologi MARA, Shah Alam, Selangor Darul Ehsan, Malaysia
}

\section{Article Info}

Article history:

Received Oct 3, 2019

Revised Dec 20, 2019

Accepted Jan 3, 2020

\section{Keywords:}

Artificial Neural Network

Business Performance

Digital Marketing

Entrepeneurship

Klang Valley

\begin{abstract}
Artificial Intelligence is great when it comes to routine activities and vast amounts of data are analyzed. This can be done more quickly and efficiently than men. In the world of digital marketing, Artificial Intelligence is quickly coming into play. With Artificial Intelligence joining the digital marketing environment, predicting user behavior, search cycles, and much more will be easier. This can support websites that are highly user-friendly for organizations. Moreover, with the aid of Artificial Intelligence, content creation has become a faster and easier task for brands. Practically, a company's degree of enterprise marketing can have an effect on its overall business efficiency. Entrepreneurial marketing is driven by entrepreneurial opportunities which involves the proactive identification and exploitation of opportunities for acquiring and retaining profitable customers through Digital approaches to risk management, resource leveraging and value creation. This research was done by collecting data using semi structure questionnaire distributed to 169 start up owners in Klang Valley area. Using two-layer 6-31 with hyperbolic tangent-purelin configurations neural network model, it was found that proactiveness, risk taking, resource leveraging, opportunity focus, intensity and value add are the significant factors towards digital marketing respectively. It is expected that the findings would give some inputs to the Malaysian entrepreneurs on innovative digital marketing in their businesses, regardless the sizes.
\end{abstract}

This is an open access article under the CC BY-SA license.

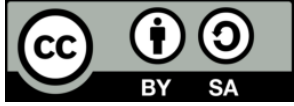

\section{Corresponding Author:}

Hazrita Ab. Rahim,

Department of Business Studies, Faculty of Business, Economics and Accounting,

HELP University, Subang 2 Campus. Persiaran Cakerawala, Subang Bestari, Seksyen U4, 40150 Shah Alam, Selangor Darul Ehsan, Malaysia.

Email: hazrita.ar@help.edu.my

\section{INTRODUCTION}

Artificial Intelligence and digital marketing are beginning to go hand in hand. Artificial Intelligence transforms digital strategy with the ability to collect data, interpret it, apply it, and then learn from it. As it continues to advance, so will the capabilities to use it to improve digital marketing strategies and valuable customer insights for companies. To be a successful entrepreneur in today's highly demanding business world, all the information needed is important as tools to stay relevant, competitive and profitable. Every large or small company's success is determined by two factors that are the volume of revenue and the 
ability to expand physically in terms of diversification of size and goods or services. Nonetheless, a niche marketing strategy needs to be developed for Small and Medium Enterprise (SME) in order to remain viable and competitive in the highly volatile business environment. There are seven elements within the scope of entrepreneurial marketing that can be used as an independent business strategy or as a combination among others. In Malaysia exploration on digital marketing and artificial intelligence as business strategy model is still limited, expecially among small and medium entrepreneurs. Therefore, in this research, the significance among important predictors towards innovative digital marketing is explored at multi-sizes of businesses around Klang Valley, Malaysia. This research paper is divided into five components which are introduction, related literatures, methodology, results and discusssions, last but not least counclusions and recommendations.

\section{RELATED LITERATURES}

Usually, marketing theories are taught from traditional textbooks [1-3] which concentrate on marketing activities such as scheduling, marketing analysis and marketing mix (4Ps and 7Ps) implementation. Such concepts are designed for large companies where there are more readily available financial resources and marketing experience. Because of the unique characteristics and constraints of small and medium-sized enterprises, including the inherent characteristics of SME owners and managers, the competitive business environment and the lack of resources inside SMEs [4-5], it is unrealistic to presume that SMEs may follow the same or similar approaches to marketing as large enterprises [6-7]. It is therefore necessary to develop and strengthen current marketing models that can be used to profile marketing practices in small businesses [8].

On the other hand, a more revolutionary interpretation of Entrepreneurial Marketing (EM) is that it considers that EM is a complete convergence of marketing and entrepreneurship. EM's framework is not merely the interface between marketing sets and entrepreneurial processes that emerged as EM's traditional conceptualization, but incorporates entirely all aspects of AM (administrative advertising) entrepreneurship [9-10] it thus becomes a strategic orientation that goes beyond the role of marketing [11]. Alternatively, the other concepts find EM as an alternative to traditional marketing and associate it with "this word (EM) is used as an integrative conceptualization that represents alternative perspectives such as guerrilla marketing, revolutionary marketing, expeditionary marketing, disruptive marketing and others" [12]. The other type of definition of EM has a different perspective and is based on the life cycle of the company. [3] Claims that when the business is small, versatile and able to experience new things as an informal method of advertising, it is practiced in its early stages and this would be described by EM as many businesses are started by people who live by their wit. As the company grows and matures, marketing practices are more rigorous [13], preparation is necessary and the company hits the second stage, called formalized marketing: "When small businesses expand, they inevitably move towards more organized marketing." The third stage is when the formalized approach is excessive and causes a change is required, another form of marketing called Intrapreneurial Marketing (IM) that could be the focus of further study. A consensus arose on how companies think and make marketing-related decisions. There are five major differences between how nonentrepreneurs think which logic is predictive and how entrepreneurs think that logic is successful [14-15]:

1. Future vision. It is predictive for the logic of prediction and imaginative for the logic of influence. The future is seen as a causal continuation of the past in the first case and can therefore be expected [16]. In the second case, the future is formed, at least in part, by agents ' voluntary actions and its prediction is therefore not possible;

2. The foundation of decision-making. Actions are determined by intention in predictive logic. Actions are determined by available means of active reasoning [17]. "Born" purposes by imagining courses of action based on the means available;

3. Attitude to risk. In statistical logic, a total benefit option is selected while in actual logic an alternative is selected based on how much the businessman can afford to lose by selecting it [18];

4. Attitude to the outsiders. Competition as in the case of predictive logic and cooperation-where rationality is effective [19];

5. Attitude towards unforeseen contingencies: avoidance as in the case of predictive logic and fructification as in the logic of impact. Precise forecasts, diligent preparation and emphasis on priorities that are unique to predictive reasoning and make contingencies known as barriers to avoid. Eviting predictions, imaginative thinking, continuous transformation of goals that are specific to effective logic and making contingencies perceived as opportunities for creating something new and are therefore appreciated [20]. 


\section{METHODOLOGY}

This research was done by collecting data using semi structure questionnaire distributed to 169 start up owners in Klang Valley area (kindly contact the corresponding author upon the details of data and questionnaires). The result was later analysed using IBM SPSS Statistics version 25 software. The flowchart of this research can be be referred in Figure 1. Table 1 and Figure 2 shows the dependent and the independent variables involed in this research.

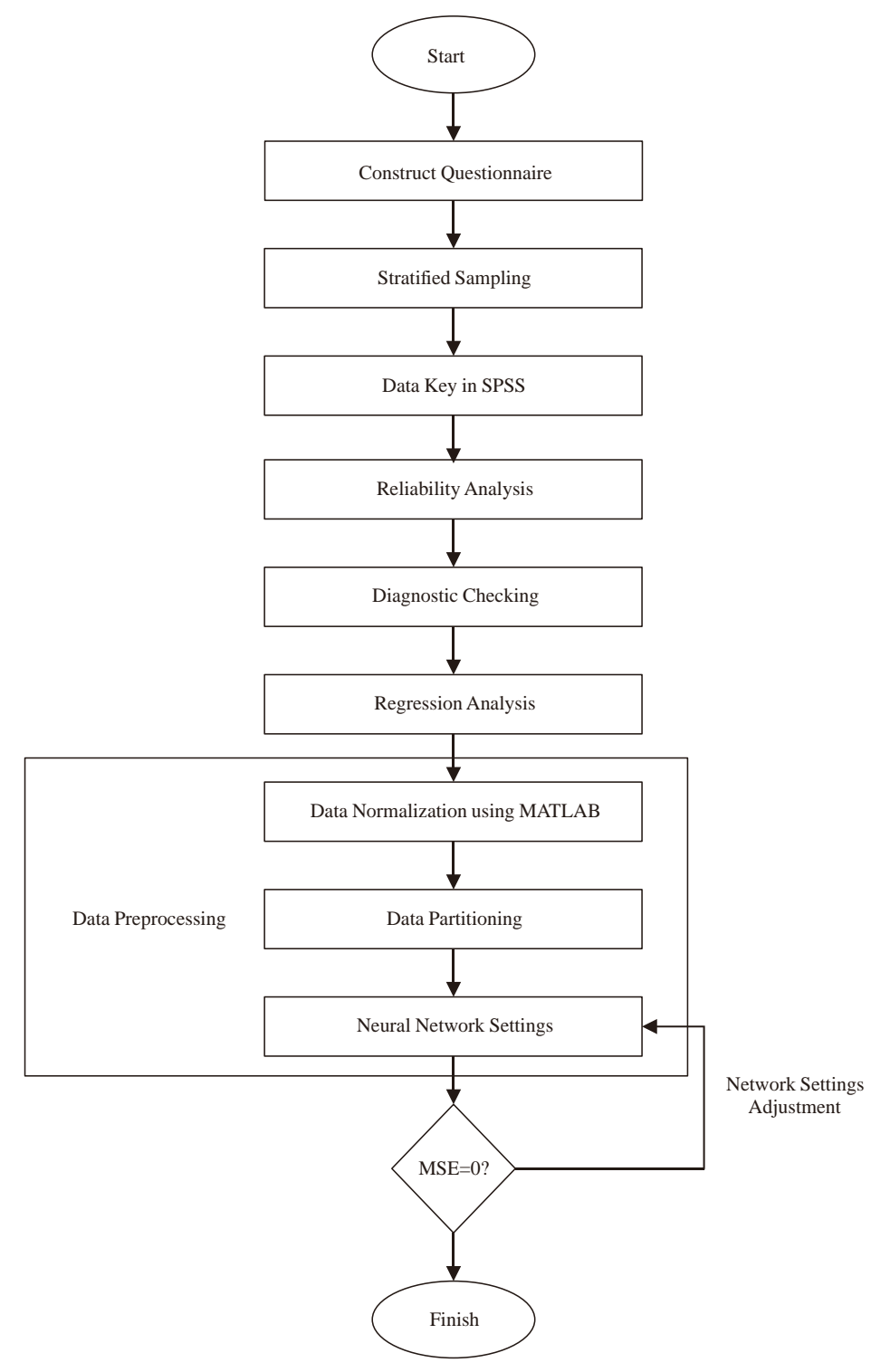

Figure 1. Research flowchart

Table 1. Variables involved in this research

\begin{tabular}{cccc}
\hline No. & Variable & Notation & Description \\
\hline 1 & IMean & $\mathrm{Y}$ & Digitalness \\
2 & SMean & $\mathrm{X}_{1}$ & Resource Leveraging \\
3 & PMean & $\mathrm{X}_{2}$ & Proactiveness \\
4 & OMean & $\mathrm{X}_{3}$ & Opportunity Focus \\
5 & INTMean & $\mathrm{X}_{4}$ & Intensity \\
6 & VMean & $\mathrm{X}_{5}$ & Value Add \\
7 & RMean & $\mathrm{X}_{6}$ & Risk Taking \\
\hline
\end{tabular}

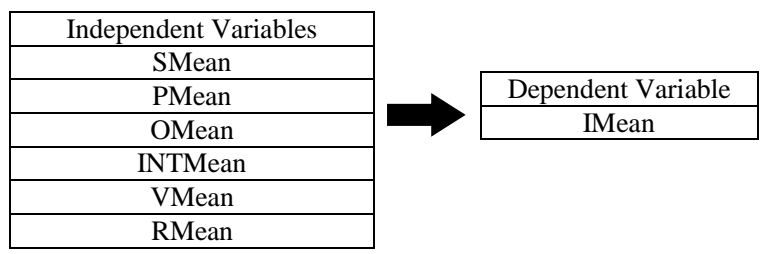

Figure 2. Independent variables and dependent variable of this research 
The general form of the model can be written as

$$
Y=1+\beta_{0} * X_{1}+\beta_{1} * X_{2}+\beta_{2} * X_{3}+\beta_{3} * X_{4}+\beta_{4} * X_{5}-\beta_{5} * X_{6},
$$

where

$$
\text { IMean }=1+\beta_{0} * \text { SMean }+\beta_{1} * \text { PMean }+\beta_{2} * \text { OMean }_{3}+\beta_{3} * \text { INTMean }+\beta_{4} * \text { VMean }-\beta_{5} * \text { RMean }
$$

\section{RESULTS AND DISCUSSIONS}

Table 2 shows the data partitioning during the pre-processing stage. From Table 3, hyperbolic tangent was used in the first layer (input layer to hidden layer) in the network, and purelin in the second layer (hidden layer to output layer). This can be proven by the network architecture in Figure 3. Moreover, Table 4 shows the model summary for both training and testing sets. Figure 4(a) illustrates the scatter plot of standardized redisuals versus the dependent variable. Furthermore, Figure 4(b) demostrates the P-P Plot of the standardized redisuals.

\begin{tabular}{|c|c|c|c|}
\hline & & $\mathrm{N}$ & Percent \\
\hline \multirow[t]{5}{*}{ Sample } & Training & 118 & $69.8 \%$ \\
\hline & Testing & 51 & $30.2 \%$ \\
\hline & & 169 & $100.0 \%$ \\
\hline & & 0 & \\
\hline & & 169 & \\
\hline
\end{tabular}

Table 2. Case processing summary

\begin{tabular}{|c|c|c|}
\hline Input Layer & $\begin{array}{l}\text { Number of Units } \\
\text { Rescaling Method for Covariates }\end{array}$ & $\begin{array}{c}\text { SMean } \\
\text { PMean } \\
\text { OMean } \\
\text { INTMean } \\
\text { VMean } \\
\text { RMean } \\
6 \\
\text { Standardized }\end{array}$ \\
\hline Hidden Layer(s) & $\begin{array}{c}\text { Number of Hidden Layers } \\
\text { Number of Units in Hidden Layer } 1^{\text {a }} \\
\text { Activation Function }\end{array}$ & $\begin{array}{c}1 \\
3 \\
\text { Hyperbolic tangent } \\
\end{array}$ \\
\hline Output Layer & $\begin{array}{c}\text { Dependent Variables } \\
\text { Number of Units } \\
\text { Rescaling Method for Scale Dependents } \\
\text { Activation Function } \\
\text { Error Function } \\
\text { a. Excluding the bias unit }\end{array}$ & $\begin{array}{c}\text { IMean } \\
1 \\
\text { Standardized } \\
\text { Identity } \\
\text { Sum of Squares }\end{array}$ \\
\hline
\end{tabular}

Table 3. Network information

Table 4. Model summary

\begin{tabular}{ccc}
\hline Training & Sum of Squares Error & 28.166 \\
& Relative Error & .481 \\
& Stopping Rule Used & Training Time \\
& Sum of Squares Error & $0: 00: 00.09$ \\
\hline Testing & Relative Error & 22.191 \\
& Dependent Variable: IMean & .706 \\
& a. Error computations are based on the testing sample. & \\
\hline
\end{tabular}




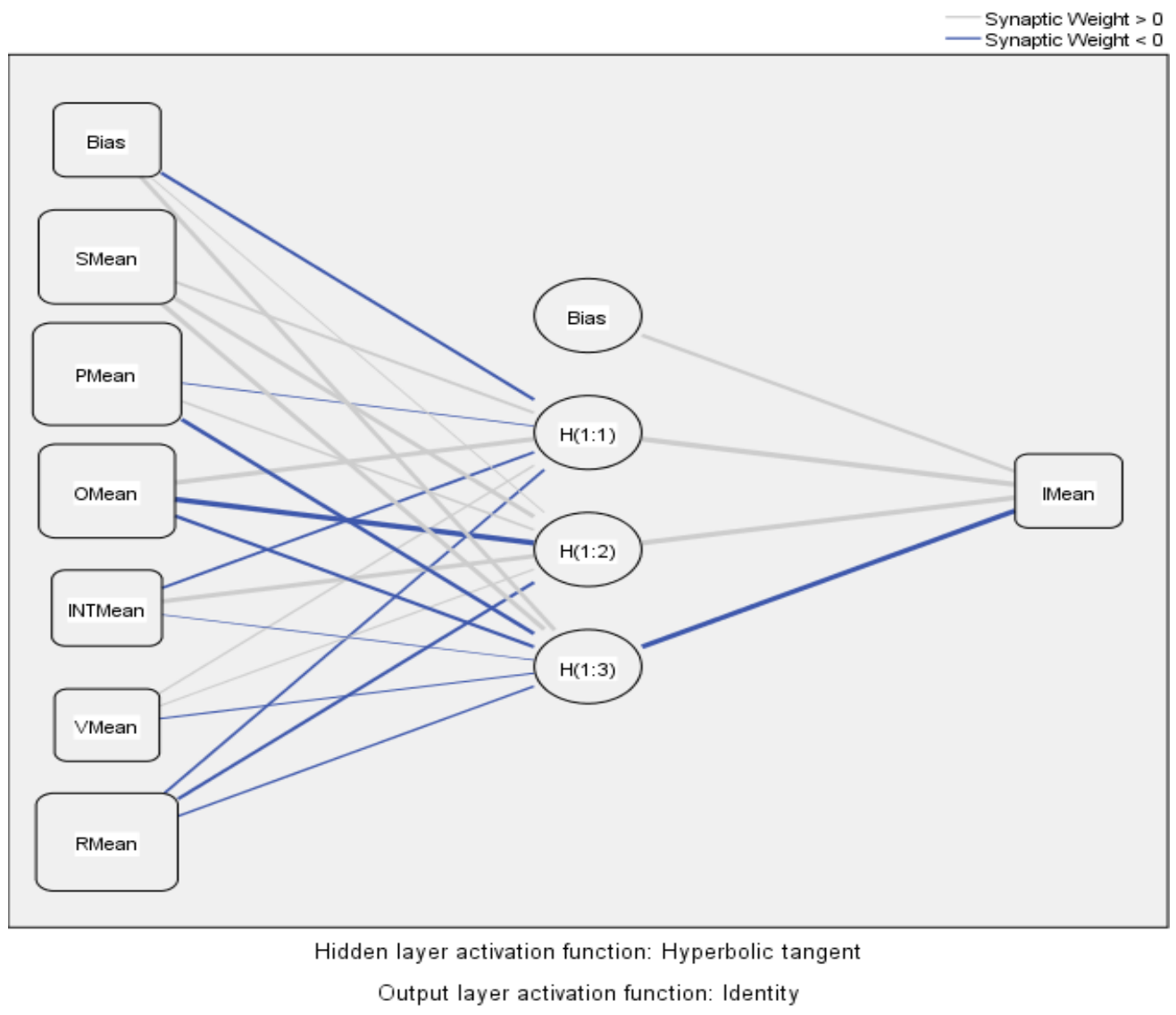

Figure 3. Network architecture

Table 5. Parameter estimates

\begin{tabular}{cccccc}
\hline & & \multicolumn{3}{c}{ Predicted } & Output Layer \\
Predictor & & $\mathrm{H}(1: 1)$ & $\mathrm{H}(1: 2)$ & $\mathrm{H}(1: 3)$ & IMean \\
\hline Input Layer & (Bias) & -.357 & .040 & .696 \\
& SMean & .318 & .727 & .734 & \\
& PMean & -.039 & .123 & -.662 & \\
& OMean & .839 & -1.283 & -.464 & \\
& INTMean & -.308 & .769 & -.006 & \\
& VMean & .105 & .075 & -.061 & .652 \\
Hidden Layer 1 & RMean & -.277 & -.361 & -.122 & 1.188 \\
& (Bias) & & & & 1.133 \\
& $\mathrm{H}(1: 1)$ & & & & -.958 \\
\hline
\end{tabular}

Table 6 shows the normalized importance respecting to innovative digital marketing. In Figure 5, it was found that proactiveness, risk taking, resource leveraging, opportunity focus, intensity and value add are the significant factors towards digital marketing respectively. Proactiveness and risk taking are proven to be very important towards innovative digital marketing for businesses. From this brief research conducted, these are the basic skill that entrepreneurs need to have an impact on a market and substantiate their success is crucial to ensuring the survival of companies [21]. Within the context of entrepreneurial advertising, the multitude of specifics can be used as a business strategy that is specifically tailored to certain categories of industy or customer segments [22]. Excellent customer service is the most important aspect of an effective digital marketing campaign [23]. Customers' decisions are more likely to convert and become repeat users and have brand loyalty when the content is important to the consumer. Customers' decisions will always effect the business decisions [24]. The parameter settings of neural network models used in this research can be further improved as suggested by [25-26]. 


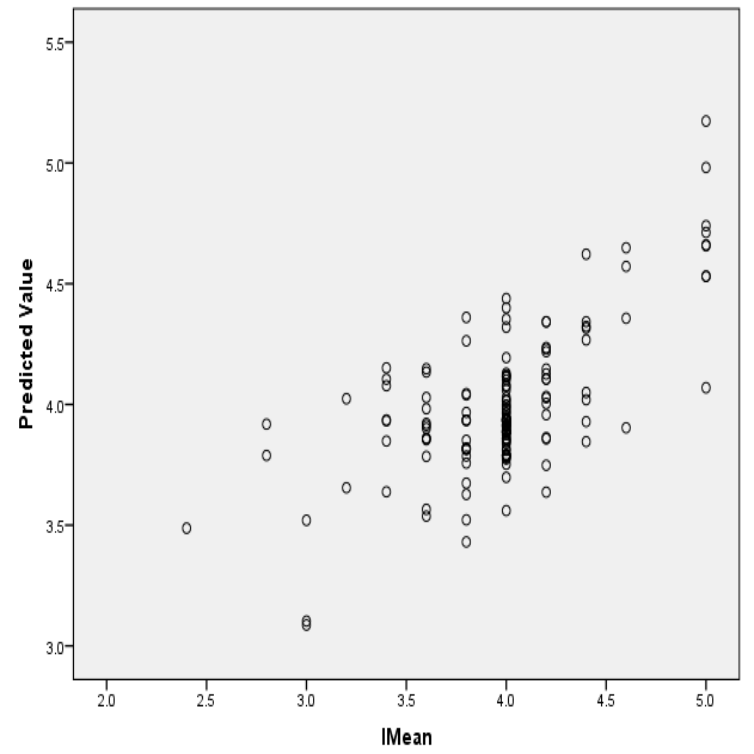

(a)

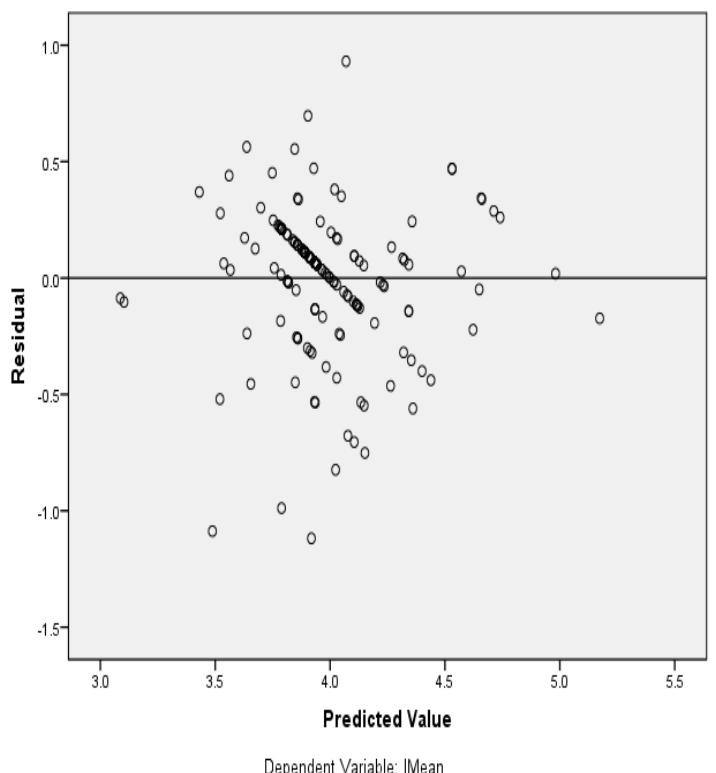

(b)

Figure 4. (a) Scatter plot of standardized redisuals vs IMean, and (b) P-P Plot of the standardized redisuals

Table 6. Independent variable importance

\begin{tabular}{ccc}
\hline & Importance & Normalized Importance \\
\hline SMean & .185 & $85.6 \%$ \\
PMean & .216 & $100.0 \%$ \\
OMean & .184 & $85.1 \%$ \\
INTMean & .115 & $53.4 \%$ \\
VMean & .102 & $47.1 \%$ \\
RMean & .198 & $91.9 \%$ \\
\hline
\end{tabular}

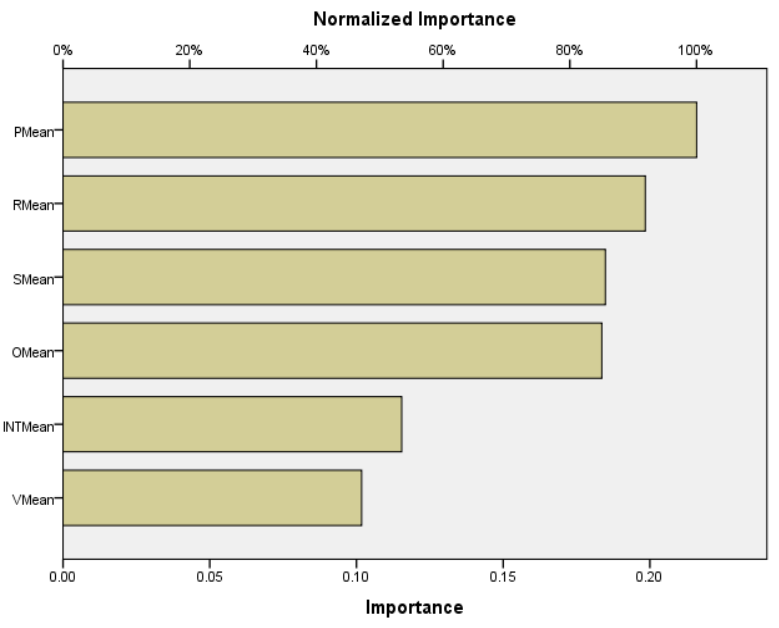

Figure 5. Bar Chart of the normalized importance

\section{CONCLUSION AND SUGGESTION FOR FUTURE RESEARCH}

As a conclusion, the objective of this research is successfully achieved. For future research, we recommend more work with various hypotheses and testing parameters for each of these skills. It is also suggested that the response group beyond the Klang Valley area. With the aid of the neural network as an enhancement agent, the combination of the top three components within entrepreneurship marketing elements can be used to form a new strategy. It is expected that the findings would give some inputs to the Malaysian entrepreneurs on innovative digital marketing in their businesses, regardless the sizes.

\section{ACKNOWLEDGEMENT}

The research was supported by Ministry of Education Malaysia (MoE), and Universiti Teknologi MARA through the Fundamental Research Grant Scheme (FRGS) (600-IRMI/FRGS 5/3 (215/2019)). 


\section{REFERENCES}

[1] L. C. Neilson, "The new tools briefing: Teaching new marketing practices and technology to students", Marketing Education Review, 19(1), pp. 43-47, 2009.

[2] D. McCorkle \& J. F. Alexander, "Using a Digital Personal Learning Network Assignment to Teach Social Curation and Lifelong Learning in Marketing," Journal of Advertising Education, 23(2), 108-120, 2019.

[3] N. G. Kotler, P. Kotler \& W. I. Kotler, Museum marketing and strategy: designing missions, building audiences, generating revenue and resources, John Wiley \& Sons, 2008.

[4] M. O’Dwyer, A. Gilmore \& D. Carson, "Digital Marketing in SMEs: An Empirical Study", Journal of Strategic Marketing, Vol. 17, Issue 5, pp. 383-396, 2009.

[5] M. O’Dwyer, A. Gilmore \& D. Carson, "Digital Marketing in SMEs - Does It Exist?" European Journal of Marketing, Vol. 43, pp. 46-61, 2009.

[6] J. Hill, "A Multidimensional Study of the Key Determinants of Effective SME Marketing Activity: Part 1", International Journal of Entrepreneurial Behaviour and Research, Vol. 7, No. 5, pp. 171-204, 2001.

[7] J. Hill, "A Multidimensional Study of the Key Determinants of Effective SME Marketing Activity: Part 1", International Journal of Entrepreneurial Behaviour and Research, Vol. 7, No. 6, pp. 211-35, 2001.

[8] J. Moriarty, R. Jones, J. Rowley \& B. Kupiec-Teahan, "Marketing In Small Hotels: A Qualitative Study", Marketing Intelligence and Planning, Vol. 26, No. 3, pp. 293-315, 2008.

[9] S. Morrish \& J. Deacon, "A Tale of Two Spirits: Entrepreneurial Marketing at 42 below Vodka and Penderyn Whisky", Journal of Small Business and Entrepreneurship, Vol. 24, No. 1, pp. 113-24, 2011.

[10] M. P. Miles \& J. Darroch, "Large Firms, Entrepreneurial Marketing Processes, and the Cycle of Competitive Advantage", European Journal of Marketing, Vol. 40 No. 5/6, pp. 485-501, 2006.

[11] M. Schindehutte, M. H. Morris \& A. Kocak, "Understanding Market-Driving Behavior: The Role of Entrepreneurship", Journal of Small Business Management, Vol. 46, Issue (1), pp. 4-26, 2008.

[12] M. Schindenhutte \& H. M. Morris, "Understanding Strategic Adaptation In Small Firms", International Journal of Entrepreneurial Behavior and Research, Vol. 7, No. 3, pp. 84-107, 2001.

[13] A. Moussavi \& A. Kermanshah, "Innovation systems approach: A philosophical appraisal", Philosophy of Management, 17(1), 59-77, 2018.

[14] S. Gherardi, How to conduct a practice-based study: Problems and methods, Edward Elgar Publishing, 2019.

[15] F. Şahin, H. Karadağ \& B. Tuncer, "Big five personality traits, entrepreneurial self-efficacy and entrepreneurial intention: A configurational approach", International Journal of Entrepreneurial Behavior \& Research, 1-25, 2019.

[16] A. Laskovaia, L. Marino, G. Shirokova \& W. Wales, "Expect the unexpected: examining the shaping role of entrepreneurial orientation on causal and effectual decision-making logic during economic crisis", Entrepreneurship \& Regional Development, 31(5-6), 456-475, 2019.

[17] Y. Liu, Z. Ouyang \& P. Cheng, "Predicting consumers' adoption of electric vehicles during the city smog crisis: An application of the protective action decision model", Journal of Environmental Psychology, 64, 30-38, 2019.

[18] D. M. Taofeeq, A. Q. Adeleke \& A. K. Hassan, "Factors Affecting Contractors risk attitude from Malaysia construction industry perspective", Social Science and Humanities Journal, 1281-1298, 2019.

[19] F. Negri, "Economic or cultural backlash? Rethinking outsiders' voting behavior." Electoral Studies, 59, 158-163, 2019.

[20] M. Herberg, G. E. Torgersen \& T. Rundmo, "Competence for the Unforeseen: Social Support and Concurrent Learning as Basic Components of Interaction under Risk", Frontiers in Communication, 4, 19, 2019.

[21] T. M. Cooney \& M. Licciardi, "The Same but Different: Understanding Entrepreneurial Behaviour in Disadvantaged Communities", Entrepreneurial Behaviour, pp. 317-345, 2019.

[22] A. Annarelli, C. Battistella \& F. Nonino, "How to Trigger the Strategic Advantage of Product Service Systems", In The Road to Servitization, Springer, Cham, 2019, pp. 95-141.

[23] S. Kingsnorth, Digital marketing strategy: an integrated approach to online marketing, Kogan Page Publishers, 2019.

[24] P. P. Rokade, "Business recommendation based on collaborative filtering and feature engineering-aproposed approach", International Journal of Electrical \& Computer Engineering, 9, pp. 2088-8708, 2019.

[25] A. S. Rawat, A. Rana, A. Kumar \& A. Bagwari, "Application of Multi Layer Artificial Neural Network in the Diagnosis System: A Systematic Review”, IAES International Journal of Artificial Intelligence(IJ-AI), vol, 7, No. 3 138-142, 2018.

[26] H. Karim, S. R. Niakan \& R. Safdari, "Comparison of Neural Network Training Algorithms for Classification of Heart Diseases", IAES International Journal of Artificial Intelligence (IJ-AI), vol, 7, No. 4, 2018. 